\title{
STUDIES ON STAPHYLOKINASE
}

\author{
K. Vesterberg AND O. VesterberG* \\ Department of Bacteriology, Karolinska Institute, \\ 10401 Stockholm 60, Sweden
}

STAPHYLOKINASE is a protein found in the culture medium after growth of many strains of Staphylococcus aureus that converts plasminogen into the active proteolytic enzyme plasmin (Gerheim, 1948; Lack, 1948). Few reports have been published of the purification of staphylokinase. Davidson (1960) and Glanville (1963) precipitated protein containing staphylokinase from supernatant fluids of cultures by adjusting the $p \mathrm{H}$ to 3.3 with $10 \mathrm{M}-\mathrm{HCl}$. Glanville precipitated staphylokinase at 75 per cent. saturation with $\left(\mathrm{NH}_{4}\right)_{2} \mathrm{SO}_{4}$. The dissolved material was further purified by chromatography on carboxymethylcellulose (CM-cellulose) columns and one homogeneous component with staphylokinase activity was obtained. This preparation proved to contain no haemolysin, leucocidin, coagulase or hyaluronate lyase, and the staphylokinase was purified about 44 times. Immunodiffusion tests showed the presence of two or four antigens, depending upon how the material had been eluted from the CM-cellulose columns.

The fibrinolytic effect of staphylokinase was investigated by Lewis et al. (1964), who used enzyme that had been prepared by precipitation with ethanol (Lewis and Ferguson, 1951; Lewis et al., 1964). The in-vivo tests were made with dogs, and this preparation of staphylokinase proved too toxic for adequate thrombolytic experiments. Whether the toxicity was dependent on the kinase itself or on some contaminating protein was not revealed.

Soru, Sternberg and Istrati (1959) purified staphylokinase by precipitation first with $\left(\mathrm{NH}_{4}\right)_{2} \mathrm{SO}_{4}$ and then with ethanol. The degree of purity of the kinase was controlled by electrophoresis, chromatography and immunodiffusion in gel, and these methods indicated homogeneity of the preparation. The aminoacid composition of staphylokinase was also investigated. Recently an article describing a purification of about 100 times was published by Lack and Glanville (1970); the yield was, however, only $15-20$ per cent.

In the present investigation, staphylokinase has been purified by means of isoelectric focusing (Vesterberg et al., 1967). Further characterisation of the kinase with respect to isoelectric point $(p \mathrm{I}), p \mathrm{H}$ optimum for activity, influence of metal ions, and heat stability is reported, and some kinetic studies are also presented.

\section{MATERIALS AND METHODS}

Production of staphylokinase. S. aureus, strain V8, was grown and the culture supernatant was concentrated in principle as described earlier (Vesterberg et al.). Cultivation was made

Received 7 Jan. 1972; accepted 10 Apr. 1972.

* Present address: Chemical Division, Occupational Health Department, National Board of Occupational Safety and Health, S-100 26 Stockholm 34, Sweden.

Requests for reprints should be sent to $O . V$.

J. MED. MICROBIOL.-vOL. 5 (1972) 
in a casein hydrolysate, yeast extract medium $\mathrm{CCY}_{\mathrm{I}}$ at $p \mathrm{H} 7.5$ and $37^{\circ} \mathrm{C}$ for $18 \mathrm{hr}$ in a stirred aerated fermenter of 2.5-1 working volume (Biotec FL103, Stockholm, Sweden).

Assay of staphylokinase. The method of casein hydrolysis according to Davidson, with the modifications described by Vesterberg et al., was used. Thus, the staphylokinase solutions were incubated with plasminogen for $6 \mathrm{~min}$. Casein was then added to the testtubes and the incubation continued for $30 \mathrm{~min}$. before the addition of perchloric acid was made. The solutions were then centrifuged, and the absorbancy at $280 \mathrm{~nm}\left(\mathrm{~A}_{280}\right)$ was measured on the clear supernatants. The staphylokinase activity is expressed as the increase in $A_{280}$ per $30 \mathrm{~min}$. The amount of enzyme that gives an increase in $A_{280}$ per $30 \mathrm{~min}$. of 1.0 is called one unit of enzyme.

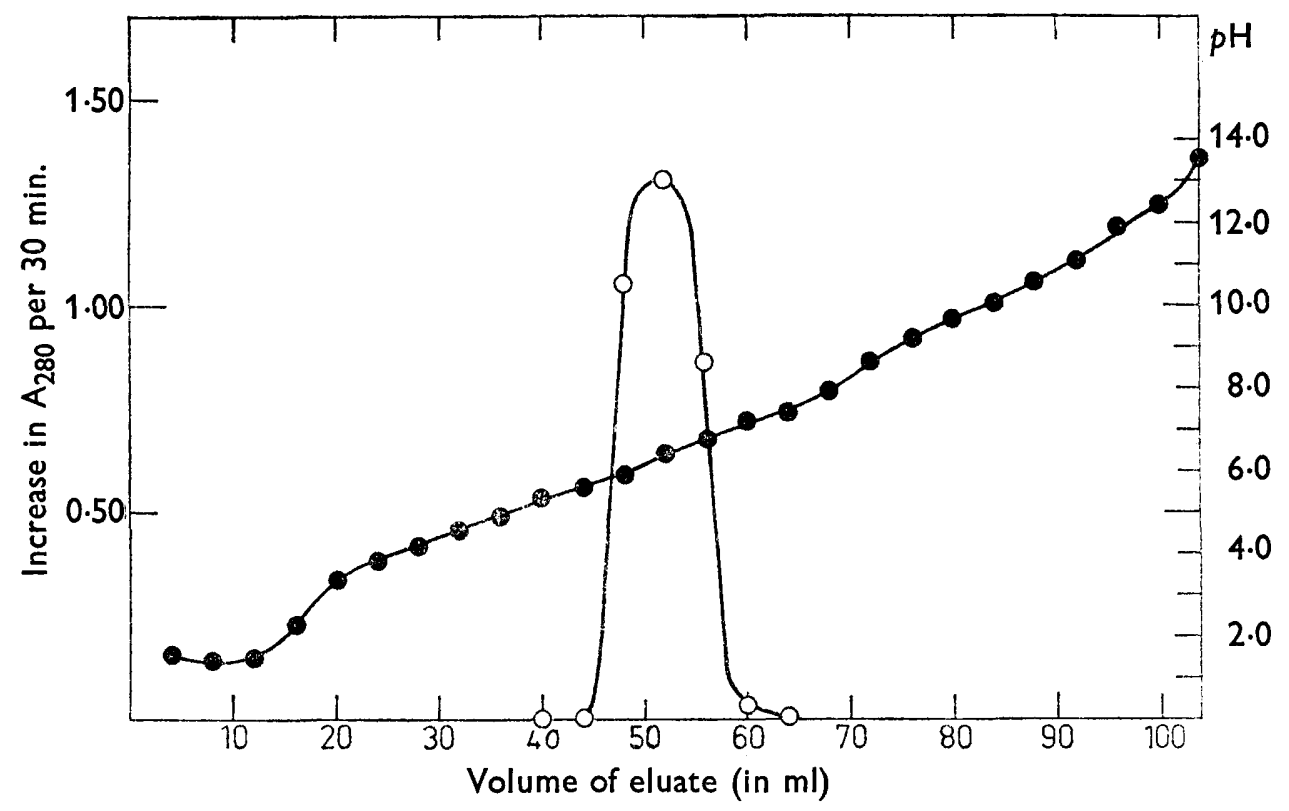

Fig. 1.-Staphylokinase activity, expressed as increase of absorbancy at $280 \mathrm{~nm}\left(\mathrm{~A}_{280}\right)$ per $30 \mathrm{~min}$., $\bigcirc-\mathrm{O}$, after the first isoelectric separation in $p \mathrm{H}$ gradient ranging from $p \mathrm{H} 2$ to $13 ; p \mathrm{H}$ at $+4^{\circ} \mathrm{C}$, $0.02 \mathrm{ml}$ of the fractions were used in each assay.

Plasminogen (human, freeze-dried, grade A) was kindly provided by AB Kabi, Stockholm. The activity was expressed in caseinolytic units (c.u.) according to Sgouris et al. (1960).

Protein determination. Dialysed samples of the culture supernatant fluids and of concentrated solutions were analysed for protein by the biuret method and by the method of Lowry et al. (1951). Fractions from isoelectric columns were analysed by measuring the $\mathrm{A}_{280}$ after prolonged dialysis.

Spectrophotometric analyses were made in a Zeiss Spektral photometer model PMQII.

Measurements of $p H$ were performed with a Radiometer $p \mathrm{H}$-meter, model PHM 25 SE with a relative accuracy of $\pm 0.02 p \mathrm{H}$ units.

Study of pH for optimal activity. Samples of the main components of staphylokinase A and $\mathrm{C}$ respectively (cf. fig. 2) were incubated with mixtures of plasminogen and the various buffer solutions indicated in fig. 5 . Casein solution was added after $6 \mathrm{~min}$. and the assay continued as indicated above.

Isoelectric focusing and separation of proteins. This method was used to separate staphylokinase from other extracellular proteins produced by $S$. aureus as described earlier (Vesterberg et al.). However, in this study Ampholine $p \mathrm{H}$ 5-7 (LKB-Produkter, S-161 25 Bromma 1, Sweden) was used to obtain a higher resolution. 


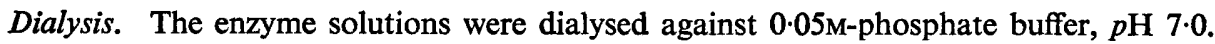
Before isoelectric focusing the samples were dialysed against 1 per cent. (w/v) glycine.

Chemicals used, unless otherwise stated, were of reagent grade. The metal salts were from Merck, Darmstadt, Germany.

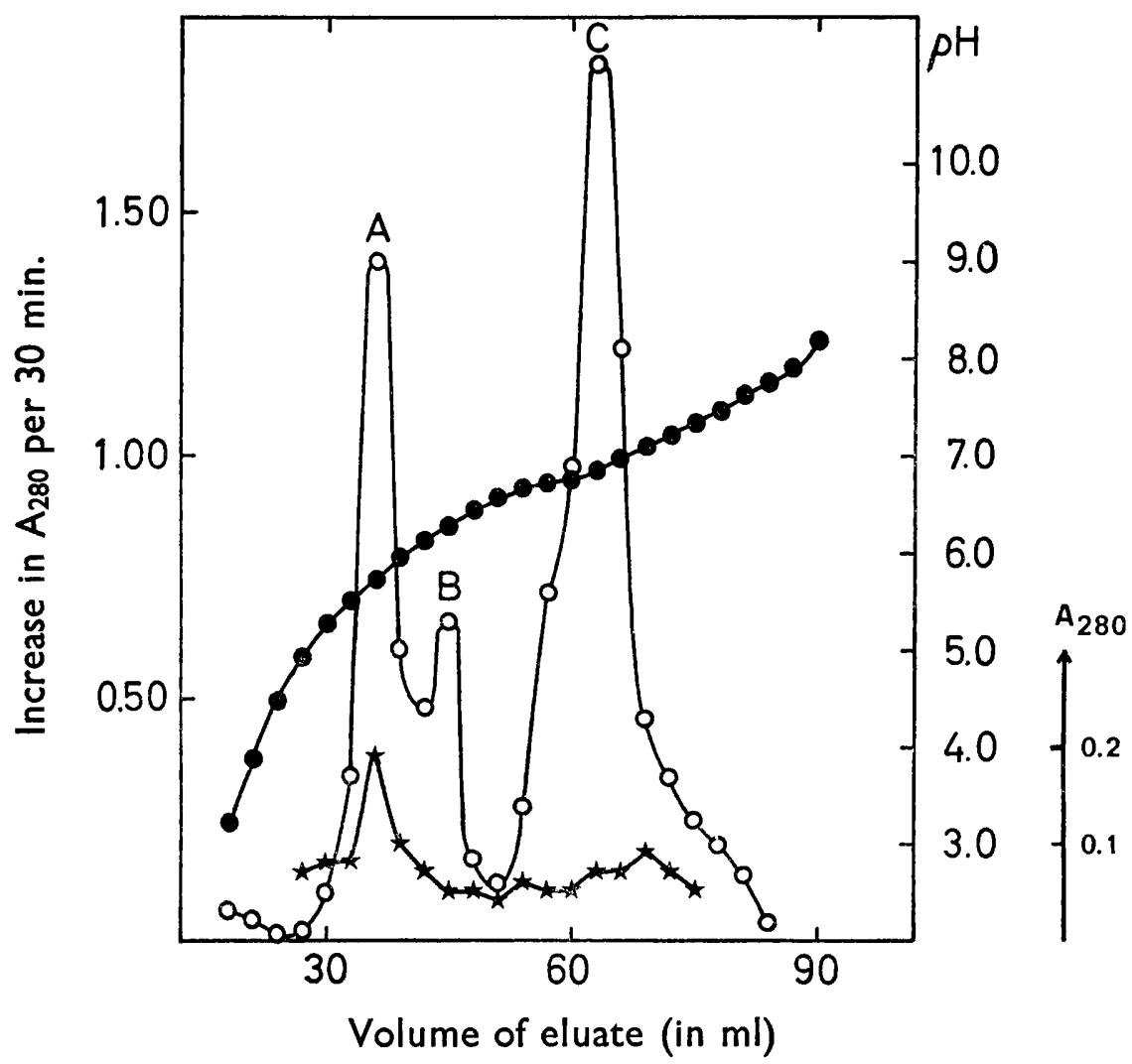

FIG. 2.-Staphylokinase activity (increase in $\mathbf{A}_{280}$ per $30 \mathrm{~min}$.), $\bigcirc-O$, after a second isoelectric focusing (see text) in a $p \mathrm{H}$ gradient mainly ranging from $p \mathrm{H} 5$ to $8 ; p \mathrm{H}$ at $+4^{\circ} \mathrm{C}$, -0. $0.01 \mathrm{ml}$ of the fractions were used in each assay. Protein content $\left(\mathrm{A}_{280 \mathrm{~nm}}\right) \star \star$

\section{RESULTS}

Isoelectric focusing of staphylokinase

The concentrated and dialysed culture supernatant originating from 2.51 was applied to a column for isoelectric focusing (LKB-Produkter) of 110-ml capacity (Vesterberg et al.). After the first separation in a $p \mathrm{H}$ gradient ranging from $p \mathrm{H} 2$ to 10 , one broad peak of staphylokinase activity was obtained (fig. 1) with a maximum at $p \mathrm{H} \mathrm{6.5}$. The active fractions were pooled and then applied to a new column. This was prepared with ampholytes giving a narrower $p \mathrm{H}$ gradient mainly ranging from $p \mathrm{H} 5$ to 8 . The staphylokinase was now found in three peaks with $p \mathrm{I}$ at $p \mathrm{H} 5.8$ (A), 6.2 (B) and 6.8 (C) (fig. 2). The two most acidic components were not quite separated. The reproducibility of $p \mathrm{I}$ in different experiments with material from four different cultivations was 
very good, but the relative amounts of staphylokinase in different peaks varied, e.g., in some experiments peak A contained twice as much activity as peak C.

\section{Degree of purification of staphylokinase}

The staphylokinase activity per $\mathrm{ml}$ of crude supernatant was 3.5 units (mean value of several cultivations). The protein concentration of this material was about $0.1 \mathrm{mg}$ per $\mathrm{ml}$. This gives an approximate specific staphylokinase activity of 35 units per $\mathrm{mg}$ of protein. Purified component $\mathrm{C}$ had a specific activity of about 1.9 units per $\mu \mathrm{g}$ of protein. Staphylokinase was thus purified about 55 times. The specific activity of component $\mathrm{A}$ was somewhat less. For component $\mathrm{B}$ no value can be given because of the very low protein concentration and low activity. In most runs the protein concentration of fractions from the isoelectric column was estimated by absorbancy measurements at $280 \mathrm{~nm}$, where $A_{280}=1.00$ is assumed to correspond to $1 \mathrm{mg}$ of protein per $\mathrm{ml}$. The carrier ampholytes interfere with the Lowry method, but after long dialysis of the fractions ( $36 \mathrm{hr}$ ) this method gives almost the same result as $\mathbf{A}_{280}$ measurement, except in the acidic region of the gradient, where $\mathbf{A}_{280}$ gives a higher value partly due to oxidation products formed at the anode. The three components of purified staphylokinase were free from alpha haemolysin (Wadström, 1968), leucocidin, lipase, phosphatase and protease (Vesterberg et al.). DNA-ase activity was also studied (Wadström, 1967) and only staphylokinase B contained a minor part of this activity.

\section{Properties of staphylokinase preparations}

Stability. When the fractions containing staphylokinase, sucrose and Ampholine were stored at $-20^{\circ} \mathrm{C}$ for $6 \mathrm{mth}$ only small losses of activity were observed. However, component B was less stable than the other components. Repeated freezings and thawings of components $\mathrm{A}$ and $\mathrm{C}$ did not seem to have any effect on their activity. Fractions $A, B$ and $C$ and unpurified staphylokinase could be heated to $90^{\circ} \mathrm{C}$ for $10 \mathrm{~min}$. without any detectable loss of activity. However, later experiments have shown that when staphylokinase is further purified by means of ion-exchange chromatography it is much more labile (Eriksson, Möllby and Vesterberg, to be published). When electrofocusing was applied to the heated culture supernatant no significant changes in the isoelectric point of staphylokinase were observed.

Recovery of activity after isoelectric focusing. The total staphylokinase activity increased about 100 per cent. after the first isoelectric separation. This was confirmed in several experiments. As a rule, no significant loss of activity was observed during the second separation. To find out whether the increase in activity was due to the presence of some inhibiting factor in the culture supernatant that was removed during electrofocusing, concentrated culture supernatant was heated to $96^{\circ} \mathrm{C}$ for $10 \mathrm{~min}$. Portions of this material were mixed with purified staphylokinase (components $\mathrm{A}$ and $\mathrm{C}$ separately). The mixtures were kept at $37^{\circ} \mathrm{C}$ for $15 \mathrm{~min}$. before assay. Untreated concentrated supernatant was also mixed with purified staphylokinase in the same way and 
assayed. Controls without any additions were also included. Neither heated nor unheated supernatant had any effect on the activity of purified staphylokinase. Thus, this experiment gave no explanation for the gain of activity during isoelectric focusing.

Effect of some metal ions, ethylenediaminetetra-acetate (EDTA) and cysteine. When the metal salts or the other agents listed in the table were added simultaneously with the casein solution the effect observed was the influence on the caseinolytic activity of plasmin (the table, "inhibition of ... plasmin").

TABLE

Inhibition of staphylokinase activity by metal ions and by cysteine

\begin{tabular}{|c|c|c|c|}
\hline \multirow{3}{*}{ Substance added } & \multicolumn{3}{|c|}{ Percentage inhibition, by the substance added, of } \\
\hline & \multicolumn{2}{|c|}{ the total activity* of component } & \multirow{2}{*}{ plasmin $\dagger$} \\
\hline & $\underset{(p I: 5 \cdot 8)}{A}$ & $\underset{(p \mathrm{I}: 6 \cdot 8)}{\mathrm{C}}$ & \\
\hline \begin{tabular}{l}
\multicolumn{1}{c}{$\mathrm{H}_{2} \mathrm{O}$} \\
$0.02 \mathrm{M}-\mathrm{NaCl}$ \\
$0.02 \mathrm{M}-\mathrm{CaCl}_{2}$ \\
$0.02 \mathrm{M}-\mathrm{MgSO}_{4}$ \\
$0.02 \mathrm{M}-\mathrm{MnSO}_{4}$ \\
$0.02 \mathrm{M}-\mathrm{CuSO}_{4}$ \\
$0 \cdot 01 \mathrm{M}-\mathrm{Pb}\left(\mathrm{Ac}_{2}\right.$ \\
$0.01 \mathrm{M}-\mathrm{ZnSO}_{4}$ \\
$0.02 \mathrm{M}-\mathrm{AgNO}_{3}$ \\
$0.02 \mathrm{M}-\mathrm{cysteine}$ \\
$0.02 \mathrm{M}-\mathrm{CoCl}_{2}$
\end{tabular} & $\begin{array}{r}0 \\
0 \\
88 \\
5 \\
94 \\
100 \\
60 \\
88 \\
100 \\
24 \\
97\end{array}$ & $\begin{array}{r}0 \\
0 \\
88 \\
2 \\
93 \\
100 \\
70 \\
98 \\
100 \\
30 \\
96\end{array}$ & $\begin{array}{r}0 \\
0 \\
66 \\
0 \\
96 \\
100 \\
45 \\
91 \\
100 \\
46 \\
97\end{array}$ \\
\hline
\end{tabular}

On the other hand, when the metal-salt solution was added simultaneously with staphylokinase the effect could be caused by its influence (1) on the conversion of plasminogen to plasmin promoted by staphylokinase, (2) on the caseinolytic activity of plasmin, or (3) on both (the table, " inhibition of ... total activity"). Many of the metal salts studied had an inhibitory effect on plasmin as well as on the total activity. In no case was it possible to see an isolated effect on staphylokinase, when allowance is made for a certain degree of uncertainty in the activity determination. None of the agents had an enhancing effect on the activity. The influence of different concentrations of lead acetate on the total reaction when staphylokinase component $\mathrm{C}$ was used is shown in fig. 3. The same type of curve was obtained with component A. The sodium salt of EDTA in concentrations higher than $0.01 \mathrm{M}$ had an inhibitory effect on the staphylokinase activity in unpurified material. Lower concentrations of EDTA had no effect.

$p H$ for optimal activity. The $p H$-optima of the two main components 
(A and $\mathrm{C}$ ) were investigated. The optimal $p \mathrm{H}$ lies between $p \mathrm{H} 7.5$ and 8.5 (fig. 4). There was no significant difference between the two components. The peak at $p \mathrm{H} 7.4$ (fig. 4) could be the optimal $p \mathrm{H}$ of plasmin. Work is in progress to verify this hypothesis.

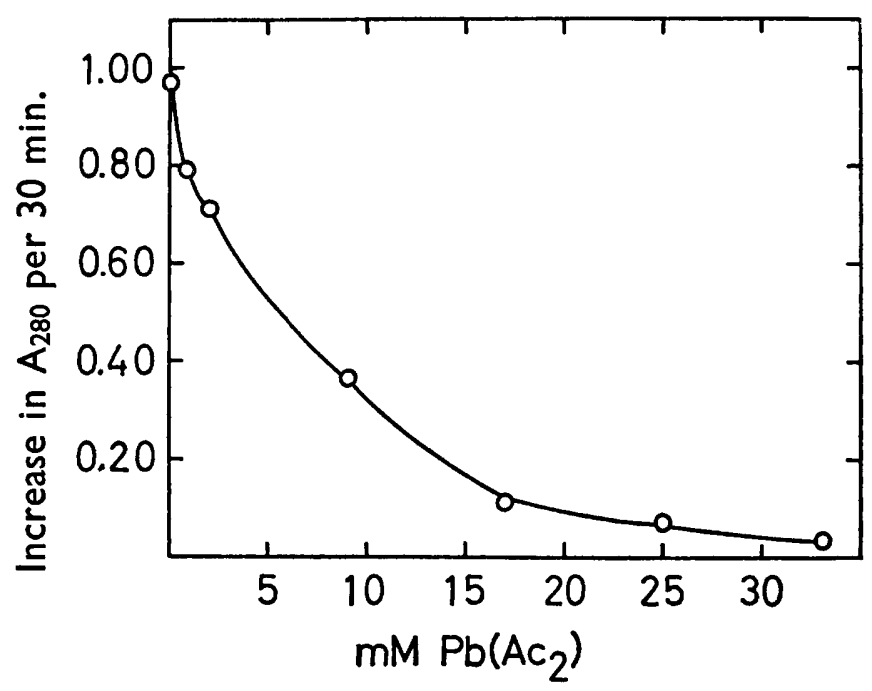

FIG. 3.-The effect of lead acetate $\left(\mathrm{Pb}(\mathrm{Ac})_{2}\right)$ on total reaction (i.e., salt added before activation). Staphylokinase activity (increase in $\mathrm{A}_{280}$ per $30 \mathrm{~min}$.), $\mathrm{O}-\mathrm{O}$. The figures at the abscissa indicate the final concentration of $\mathrm{Pb}(\mathrm{Ac})_{2} .0 .05 \mathrm{ml}$ of staphylokinase $\mathrm{C}$ is here used as activating agent (see text).

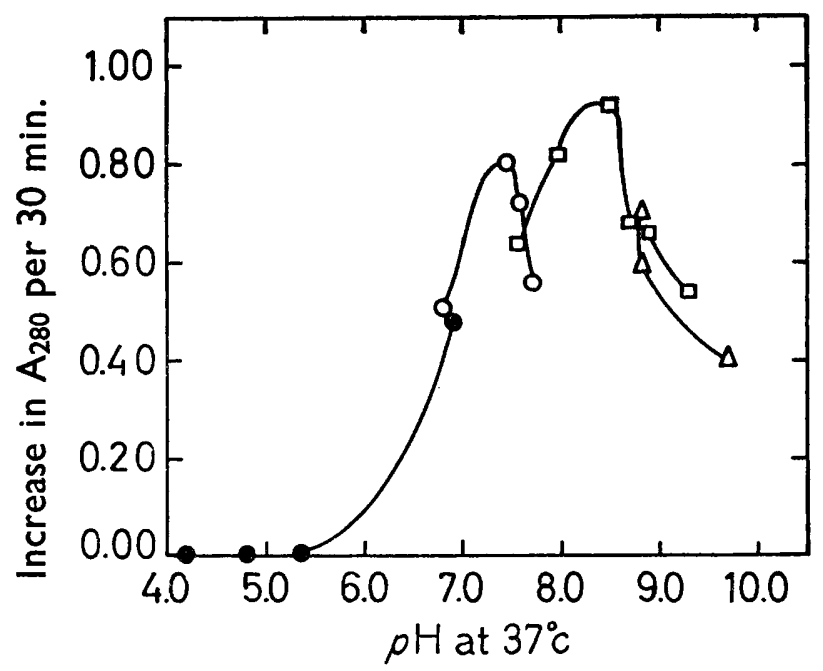

FIG. 4. $-p \mathrm{H}$ optimum of staphylokinase component $\mathrm{C}(p \mathrm{I}: 6.8) .0 .05 \mathrm{ml}$ of the staphylokinase solution was used for each assay. The $p \mathrm{H}$ values given are those in the reaction mixture before the addition of casein. Staphylokinase activity (increase in $\mathrm{A}_{280}$ per $30 \mathrm{~min}$.) when the following buffers were used: acetic acid-sodium acetate $(p \mathrm{H} \mathrm{4 \cdot 2-6 \cdot 9)}$; potassium dihydrogen phosphate-disodium hydrogen phosphate $(p \mathrm{H} \mathrm{6.8-7 \cdot 7)} \bigcirc-\mathrm{O}$; tris (hydroxymethyl) aminomethane hydrochloric acid-tris (hydroxymethyl) aminomethane $(p H$ 7.6-9.2) $\square \square \square$; and glycine-sodium glycinate $(p H$ 8.7-9.4) $\triangle \longrightarrow \triangle$. All buffers had an ionic strength of $0 \cdot 1$. 
Kinetics. Fig. 5 shows the kinetics of activation of plasminogen by purified staphylokinase. Activation of plasminogen occurs in a few seconds. The kinetics of the reaction with components $A$ and $C$ were almost identical. Under

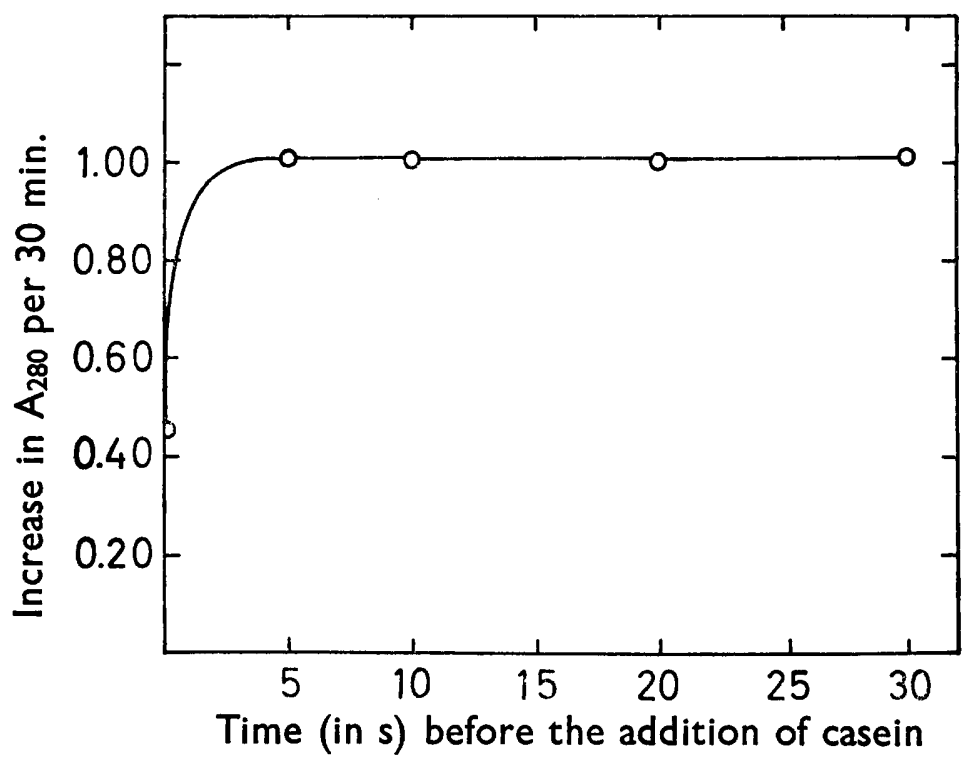

FIG. 5.-Activation of plasminogen by purified staphylokinase (component A). $0.02 \mathrm{ml}$ of staphylokinase solution was incubated for various times with 8 caseinolytic units (c.u.) of human plasminogen, after which casein was added. Staphylokinase activity (increase in $\mathbf{A}_{280}$ per min.), $\mathrm{O}-\mathrm{O}$. The $\mathrm{A}_{280}^{1.0 \mathrm{~cm}}$ of the staphylokinase solution used was 0.09 .

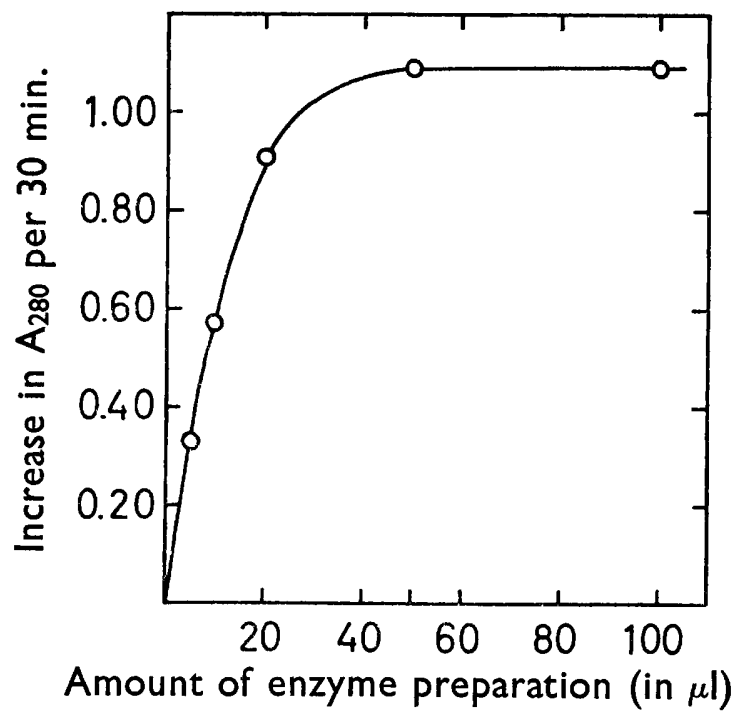

FIG. 6.-Effect of concentration of staphylokinase on rate of hydrolysis of casein (increase in $\mathrm{A}_{280}$ per $30 \mathrm{~min}$.). Different amounts of purified staphylokinase (component A) incubated with 8 c.u. of human plasminogen for $6 \mathrm{~min}$. The $A_{2}^{1} 8_{0}^{0} \mathrm{~cm}$ of the staphylokinase solution used was 0.09 . 
the test conditions the rate of hydrolysis of casein was proportional to the staphylokinase concentration up to an increase in $A_{280}$ per 30 min. $=1 \cdot 00$ (fig. 6). This was true both for purified and unpurified staphylokinase.

\section{Discussion}

Glanville (1963) found staphylokinase activity in a single component after ion-exchange chromatography on CM-cellulose columns, but the enzyme seemed to be inhomogeneous on immunodiffusion. This was probably due to the presence of some contaminating protein. The work of Soru et al. (1959) seemed to indicate that staphylokinase was a homogeneous substance.

The present investigation showed that staphylokinase can be separated into three components by means of isoelectric focusing. All three components were identified in repeated experiments over a narrow $p \mathrm{H}$ range (5-7), but the relative amounts in the peaks varied from experiment to experiment. Further investigations will be made in order to find out the cause of the heterogeneity. Recent experiments indicate that staphylokinase can be separated into three components by means of disk electrophoresis and that these show identity in gel immunodiffusion (Arvidson et al., to be published). The increase in activity after isoelectric focusing seems to suggest that there are inhibiting factors in the culture medium that are removed during this process.

It is difficult to estimate the degree of purification of staphylokinase, partly because of the small amount of protein in the fractions after isoelectric focusing, and partly because different methods for protein analysis were used at different stages in the purification. The protein concentration in the dialysed culture supernatant is about $0.1 \mathrm{mg}$ per $\mathrm{ml}$ according to the Lowry method (Lowry et al., 1951). $\mathrm{A}_{280}$ measurement on the same material gives a value about 100 times higher. The biuret method was used on concentrated culture supernatants, but this method was too insensitive for use in the later stages of purification. The carrier ampholytes interfered with the Lowry method for protein analysis, so extensive dialysis of the fractions from the isoelectric focusing columns had to be made. The protein concentration could then be estimated by the Lowry method. The accuracy and reproducibility of these tests was not satisfactory because of the low protein content in the fractions after the second electrofocusing. More accurate values will be reported when more staphylokinase is available. Efforts have therefore later been made to increase the production of staphylokinase and to use bigger culture volumes (Arvidson et al., to be published).

The study of the optimal $p \mathrm{H}$ for staphylokinase activity and the influence of metal ions is rather complicated since, in fact, two reactions are studied in the assay: firstly, the activation of plasminogen to plasmin by staphylokinase, and, secondly, the digestion of casein by plasmin. By adding metal salt simultaneously with the casein it was possible to observe the influence of this on the caseinolytic activity (the table), but it was not possible to isolate the influence of metal salts on the activation of plasminogen to plasmin by staphylokinase.

Moreover, the $p \mathrm{H}$ is changed by adding different buffers to a solution containing plasminogen and staphylokinase. When the buffered solution of casein 
(the substrate of plasmin) is added, the $p \mathrm{H}$ ought to be reset to $7 \cdot 4$, which is the $p \mathrm{H}$ used in all other assays. If plasmin has a different $p \mathrm{H}$-optimum from staphylokinase, this might cause the appearance in the diagram of an extra peak of activity. One of the peaks in fig. 4 might therefore be due to the $p H$ optimum for plasmin activity. This possibility calls for further investigation. We have not been able to find a record of the $p \mathrm{H}$-optimum of human plasmin (caseinolytic activity) in the literature.

Work is in progress to purify staphylokinase further by chromatography on Sephadex gels and by ion chromatography combined with isoelectric focusing (Eriksson, Möllby and Vesterberg, to be published).

\section{SUMMARY}

Staphylokinase in the supernatant of cultures of Staphylococcus aureus was concentrated and then purified twice successively by isoelectric focusing. The total activity of staphylokinase was increased about 100 per cent. after the first isoelectric focusing. The cause of this was investigated. It was also shown by means of this separation technique that staphylokinase is a heterogenous protein, with isoelectric points at $p H 5.8$ (component A), 6.2 (component B) and $6 \cdot 8$ (component $C$ ). The degree of purification was calculated.

Some properties of the components were studied. The effects of the following metal ions: $\mathrm{Ca}^{++}, \mathrm{Mg}^{++}, \mathrm{Mn}^{++}, \mathrm{Cu}^{++}, \mathrm{Pb}^{++}, \mathrm{Zn}^{++}, \mathrm{Ag}^{+}$and $\mathrm{Co}^{++}$; and of EDTA and cysteine, were examined. No significant differences in these respects between the three components were observed. The $p \mathrm{H}$ for optimal activity also seemed to be the same for the main components.

We are indebted to Professor B. Malmgren and Professor H. Rilbe for their great interest in this work. Thanks are also due to Dr T. Wadström for stimulating criticism. This work was supported by grants from the Swedish Board for Technical Development.

\section{REFERENCES}

DAVIDSON, FloRA M. 1960. The activation of plasminogen by staphylokinase: comparison with streptokinase. Biochem. J., 76, 56.

Gerheim, E. B. 1948. Staphylococcal coagulation and fibrinolysis. Nature, Lond., 162, 732. Glanville, KitTy L. A. 1963. A simple method of purifying staphylokinase. Biochem. J., $88,11$.

LACK, C. H. 1948. Staphylokinase: an activator of plasma protease. Nature, Lond., 161, 559.

LaCK, C. H., and Glanville, KitTy L. A. 1970. Staphylokinase. In Methods in enzymology, edited by S. P. Colowick and N. O. Kaplan, New York, vol. 19, p. 706.

Lewis, Jessica H., AND Ferguson, J. H. 1951. A proteolytic enzyme system of the blood. III. Activation of dog serum profibrinolysin by staphlokinase. Amer. J. Physiol., 166, 594.

Lewis, Jessica H., Kerber, C. W., AND Wilson, J. H. 1964. Effects of fibrinolytic agents and heparin on intravascular clot lysis. Amer. J. Physiol., 207, 1044.

Lowry, O. H., Rosebrough, N. J., Farr, A. L., and Randall, Rose J., 1951. Protein measurement with the Folin phenol reagent. J. Biol. Chem., 193, 265.

SORU, E., Sternberg, M., AND Istrati, M. 1959. Contribution à l'étude chimique de la staphylokynase. Naturwissenschaften, 46, 496.

Sgouris, J. T., Inman, J. K., McCall, K. B., Hyndman, L. A., and Anderson, H. D. 1960. The preparation of human fibrinolysin (plasmin). Vox sang., 5, 357. 
WADSTRÖM, T. 1967. Studies on extracellular proteins from Staphylococcus aureus. II. Separation of deoxyribonucleases by isoelectric focusing. Purification and properties of the enzymes. Biochim. biophys. Acta, 147, 441.

WADSTRÖM, T. 1968. Studies on extracellular proteins from Staphylococcus aureus. IV. Separation of $\alpha$-toxin by isoelectric focusing. Biochim. biophys. Acta, 168, 228.

Vesterberg, O., Wadström, T., Vesterberg, K., Svensson, H., and Malmgren, B. 1967. Studies on extracellular proteins from Staphylococcus aureus. I. Separation and characterization of enzymes and toxins by isoelectric focusing. Biochim. biophys. Acta, 133, 435. 